\title{
Un enfoque de la RSC en la televisión en Espańa. Visión comparada a través del análisis de Atresmedia y Mediaset
}

\author{
Pablo Aguilar Conde \\ Doctor por la Universidad de Burgos \\ Basilio Cantalapiedra Nieto \\ Doctor por la Universidad de Burgos
}

DOI: $10.1387 /$ reves. 17537

Fecha de entrada: 01/06/2016

Fecha de aceptación: 20/06/2016

\begin{abstract}
Sumario: Introducción. 1. Marco teórico. 2. Marco legal. 2.1. El sector audiovisual. 2.2. La Ley General de Comunicación Audiovisual y el menor. 2.3. El Código de Autorregulación de Contenidos Televisivos e Infancia. 3. Análisis empírico. 3.1. Responsabilidad Social Corporativa. 3.2. Metodología de análisis de los informes de la Comisión. 3.3. Análisis. 4. Resumen resultados. 5. Conclusiones. Bibliografía.
\end{abstract}

\section{Resumen:}

El objetivo de este trabajo es describir la adecuación de los planteamientos sobre responsabilidad social corporativa de los dos grandes grupos audiovisuales españoles, Atresmedia y Mediaset, con la aplicación del Código de Autorregulación de Contenidos Televisivos e Infancia en el tramo de programación considerado de protección reforzada para los menores. Se parte de la premisa de que las empresas pueden ser motores de la responsabilidad social y en especial aquellas con más presencia y repercusión para todos los grupos de interés. La voluntariedad de la responsabilidad social corporativa no debe ser contraria al cumplimiento de ciertos aspectos protectores relativos a los derechos del menor, definidos expresamente en la Ley General Audiovisual de 2010. Dicha norma, en su artículo 7, regula los aspectos relativos a los derechos del menor y como deben ser gestionados, estableciendo las franjas horarias que se consideran de protección para los menores. Por su parte, el Código de Autorregulación de Contenidos Televisivos e Infancia establece los principios rectores de la programación televisiva respecto de la infancia, gestionando así mismo el control de su observancia. El cumplimiento de la idea de responsabilidad social corporativa de los grandes grupos televisivos, concretamente en lo que se refiere 
a aspectos sociales relacionados con sus clientes como grupos de interés, admite un seguimiento que ponga en relación sus propósitos sociales corporativos con el cumplimiento de los mismos.

\title{
Palabras clave:
}

Comportamiento responsable, Gobierno corporativo, Responsabilidad Social Corporativa, Sector audiovisual

\begin{abstract}
:
The main objective of this paper is to describe the proper performance of the corporate social responsibility of the two great Spanish media groups, Atresmedia and Mediaset. This analysis will be referred to Self Regulation Code of Television Contents and Children. We assume that enterprises can be promoters of social responsibility and especially those with more presence and impact for all stakeholders. The voluntary nature of corporate social responsibility should not be contrary to the fulfillment of certain protective aspects of children's rights, those specifically defined in the Audiovisual General Law of 2010. This rule, in Article 7 regulates aspects of rights child and how they are managed, establishing different hourly segments that are considered protective for children. For its part, the Self Regulation Code of Television Contents and Children establishes the guiding principles of television programming and its evaluation and control. Compliance with the identity of corporate social responsibility of great television groups, particularly referred to social aspects related to customers as stakeholders, would also facilitate monitoring children rights regarding to corporate social responsibility.
\end{abstract}

\section{Keywords:}

Responsible behaviour, Corporate gobernance, Corporate Social Responsibility, Audiovisual sector

\section{Claves Econlit:}

M140, G390

\section{Introducción}

Una vez sintetizadas las ideas básicas en materias de responsabilidad social corporativa referidas a los grupos audiovisuales; y resumido el contenido de la normativa específica en materia audiovisual en su apartado de protección a la infancia; procedemos a analizar desde el punto de vista cualitativo los informes sobre las reclamaciones formuladas en aspectos 
relacionados con la infancia durante los ańos 2006 al 2015, ambos inclusive. Fruto de este análisis, procederemos a perfilar aquellos aspectos, que bajo nuestro punto de vista, permitirían reforzar la responsabilidad social REAL de las distintas cadenas televisivas. La estructura del trabajo que incorpora en el primer apartado el marco teórico de la responsabilidad social corporativa aplicada al caso de estudio; considerando a las empresas como motores de la responsabilidad social y en especial los grupos audiovisuales que tienen más presencia y repercusión. En el segundo apartado se expone brevemente el marco legal para los grupos audiovisuales que, amparados en la Ley General del Audiovisual desde 2010, deben cumplir con su propio Código de Autorregulación de Contenidos Televisivos e Infancia, suscrito por las primeras entidades televisivas el 9 de diciembre de 2004. En especial, el artículo 7 que regula los aspectos relativos a los derechos del menor y la actuación de las cadenas televisivas en su programación y su protección reforzada a la infancia, entre las $17,00 \mathrm{y}$ 20,00 horas.

En el tercer apartado se realiza el análisis empírico que desde el punto de vista metodológico entendemos apropiado. Para ello se ha recurrido, por una parte, al análisis de los informes publicados en las propias páginas web de los grupos y demás información disponible: cuentas anuales, informes de sostenibilidad, informe anual de gobierno corporativo e informe de remuneraciones del Consejo. Por otra parte, se analizarán los resultados desde 2005 del Código de Autorregulación de Contenidos Televisivos e Infancia que vean reflejada la actuación de las televisiones en la franja horaria de protección a la infancia reforzada. Se estudiará el efecto en dichos resultados del surgimiento de la Ley General del Audiovisual (2010) y de los procesos de integración de las cadenas televisivas en los casos de Atresmedia (2012) y Mediaset (2011). Por último, en el cuarto apartado, se exponen los principales resultados extraídos de la observación de los datos y en el quinto apartado, las conclusiones que nos permiten evaluar la idoneidad de la actuación de ambos grupos y sugerir una nueva propuesta de ética empresarial.

\section{Marco teórico}

Hasta el siglo xxi, no era frecuente oír hablar de ética, moral ni mucho menos responsabilidad social corporativa en los grupos audiovisuales. Las cadenas televisivas seleccionaban su público objetivo y las diferentes herramientas de marketing trataban de conseguir la máxima audiencia, sin aparentemente tener ninguna otro objetivo, que conseguir maximizar el valor de la compañía, que permitieran consecuentemente hacer lo 
mismo con los dividendos o valor para los socios y accionistas. Sin embargo, como constataremos a lo largo del presente trabajo, la responsabilidad social aparece presente en la mayor parte de las compañías, siendo un término necesario para la continuidad y el desarrollo a largo plazo de sus negocios.

Según la Real Academia Española, la ética es la parte de la filosofía que trata de la moral y las obligaciones del hombre; estando la moral en relación con los caracteres de las personas. En el caso de los menores, es de suma importancia, prestar atención a las diferentes acciones que construyen el carácter de las personas, que a diferencia del temperamento puede ser adquirido y desarrollado a través de diferentes acciones. Así, la televisión juega un papel primordial en esa construcción del carácter de los menores, ya que junto a sus padres y familiares, constituyen en la primera etapa de la infancia, su principal ventana al exterior.

Este interés ético reclama un cambio de actitud de las empresas, de modo que respondan a la pluralidad de todos los intereses en juego; con especial referencia a sus grupos de interés o stakeholders. Recogiendo sucintamente la definición de stakeholder, como grupos de interés hacia los que la empresa tiene obligaciones morales y que pueda afectar y ser afectado por los objetivos de la empresa; creemos de especial relevancia el planteamiento de los niños como grupo de interés de los grupos audiovisuales. Dentro de los grupos de interés, podemos clasificar a los niños, como grupo de interés externo, dentro de los clientes o incluso de la sociedad y público en general.

Consideramos a la responsabilidad social corporativa como el proceso a través del cual las organizaciones asumen la responsabilidad por las consecuencias sociales, económicas y medioambientales de su actividad. Una ciudadanía responsable debe afrontar el desafío de la interculturalidad, la construcción de una sociedad plural, que integre a los diferentes, unidos al concepto de universalidad y responsabilidad. Esta responsabilidad es un compromiso voluntario, que va más allá del cumplimiento de la legalidad vigente, como posterior analizaremos en lo referente a la Ley General Audiovisual. Es voluntario, pero no es un solo un conjunto de procedimientos, ya que su correcta implantación permitirá a la compañía introducir mejoras en sus procesos, la integración natural de la empresa con la sociedad y entorno, y en último lugar, la potenciación de las ventajas competitivas.

Ahora bien, a pesar de la voluntariedad de la responsabilidad social corporativa; existen diferentes instrumentos que pueden facilitar la comunicación de la gestión de cada empresa en el ámbito de la responsabilidad social. A título de ejemplo, señalamos los siguientes: 
- Pacto Mundial de las Naciones Unidas: instrumento de libre adscripción, que implica, entre otros aspectos, un compromiso de implantación gradual de los diez principios del Pacto Mundial y de comunicar anualmente los avances en materia de responsabilidad social a través de un informe de progreso o memoria de sostenibilidad.

— Global Reporting Iniciative GRI: principal estándar internacional para la elaboración de memorias de sostenibilidad. En 2011 GRI publicó un suplemento sectorial para medios de comunicación

-Dow Jones Sustaniability Index y FTSE4 Good Index: ambos informan sobre los resultados de las empresas líderes en sostenibilidad y menores impactos sociales y medioambientales derivados de su actuación.

— «Norma» ISO 26000: para normalizar los diferentes aspectos sobre RSC

- Informe integrado IIRC: comunicación acerca de cómo la estrategia de una organización, su gobierno corporativo, desempeńo y perspectivas, en el contexto de su entorno externo, la conducen a crear valor en el corto, medio y largo plazo.

- MERCO: monitor de referencia de evaluación reputaciones

Tal y como señala Fernández (2012), la responsabilidad se convierte en una herramienta clave de relaciones públicas a la hora de mejorar su reputación y legitimación así como para transmitir una identidad corporativa determinada. En el caso de los medios de comunicación, la RSC cobra una doble dimensión: las medidas responsables y la transmisión de información de forma rigurosa, veraz, objetiva y ética. En su trabajo realiza un análisis de contenido web centrado en el estudio de los sites corporativos de las empresas que componían la muestra (entre ellas Telecinco y Planeta) mostrando una vinculación directa de los grupos de comunicación con las actividades socialmente responsables. No obstante, el principal sector al que se dirigen es el de los accionistas, y apenas hacia los espectadores.

Núnez, Irisarri y Morales (2015) estudian la estrategia de las empresas privadas de televisión a través las memorias difundidas. Este trabajo tiene gran importancia, entre otros aspectos, por su diferenciación entre servicio público esencial de RTVE y las empresas privadas que diferencian servicio público de industria comercial. En su trabajo proponen, en línea con nuestra investigación, la distinción entre obligaciones comunes de RSC y las propias de su objeto social: contenidos de la programación.. Destacando que la RSC la utilizan en gran medida como artimańa para ganar reputación social al no generar, por ejemplo, impactos ambientales significativos pero haciendo caso omiso a sus compromisos suscritos sobre los as- 
pectos propios audiovisuales en los convenios de autorregulación. Los tres constituyentes principales de la RSC en estos grupos serían: la producción responsable de contenidos, la emisión responsable de contenidos y la emisión de contenidos responsables. Estos tres constituyentes quedan recogidos en el artículo 7 de la Ley General de Comunicación Audiovisual, como veremos en el siguiente capítulo. La ley 6/2012, de 1 de agosto modifica el artículo 7 de la LGCA para reforzar las medidas de protección de los menores ante contenidos que puedan perjudicar su desarrollo físico, mental o moral, sin restricciones de horarios; que en palabras de los autores se cualifican como contenidos de riesgo. Sin embargo, concluyen que las diferentes cadenas televisivas «No informan sobre si la programación emitida durante los horarios de protección se ajusta a la normativa».

\section{Marco legal}

\subsection{El sector audiovisual}

El sector audiovisual estatal opera en un punto equidistante e inestable situado entre la estabilidad buscada por el marco legal que le ampara y la variabilidad de la tecnología con la que trabaja, que permanece en una constante carrera por la innovación. Como en todo proceso comunicativo, en el sector audiovisual, participan los entes emisor y receptor, junto al canal por el que fluyen los contenidos. La equivalencia económica lleva a la división general que puede establecerse entre los tres partícipes primordiales de la industria audiovisual, la empresa productora como encargada de la generación de los contenidos, la distribución: que se responsabiliza de hacer llegar estos contenidos a las pantallas finales y la exhibición, eslabón final que pone el producto audiovisual a disposición del potencial espectador.

Este sector no es homogéneo. Aunque se tengan en común las tres partes de la cadena, producción, distribución y exhibición, lo audiovisual abarca productos tan dispares como el cinematográfico, el televisivo, la publicidad y la generación de videos institucionales o industriales, entre otros. Tomando como ejemplo los dos principales, el cine y la televisión, son dos los ministerios que afrontan sus cuestiones legales. El de Educación, Cultura y Deportes regula la normativa cinematográfica y los aspectos institucionales que le afecta, mientras que el negocio televisivo es primordialmente gestionado por el Ministerio de Industria, Energía y Turismo a través de la Secretaría de Estado de Telecomunicaciones y para la Sociedad de la Información. Esta dispersión normativa ha generado habitualmente graves problemas ya que, por ejemplo, la financiación de la pro- 
ducción cinematográfica depende en buena medida (aproximadamente en un tercio del presupuesto) de la existencia o no de la inversión televisiva en un proyecto mediante la pre-compra de los derechos de emisión del largometraje, por lo que una deseable retroalimentación entre todas las partes de la industria se veía dificultada por la disparidad normativa que afectaba a empresas que conviven en el mismo ecosistema. La Ley 7/2010, de 31 de marzo, General de Comunicación Audiovisual, sienta las bases para comenzar a unificar legalmente el sector.

Frente a la estabilidad que promete, la ley se sitúa en un aspecto mucho más inestable aunque no caótico, el de la tecnología. Si bien las innovaciones que se implementan en la fase productiva de los contenidos no dejan de tener importancia (como las mejoras en las cámaras y programas de edición y postproducción de la imagen o el casi definitivo paso de lo analógico a lo digital en cuanto al soporte en el que se rueda lo cinematográfico, pasando del negativo en $35 \mathrm{~mm}$, usado desde los albores del cine en la sesiones de los hermanos Lumière, al soporte digital) es en la distribución y exhibición de las producciones televisivas donde intervienen de manera más palpable las innovaciones. Nos referimos esencialmente a como las mejoras en los sistemas de transmisión de los datos y en las telecomunicaciones, multiplican los canales y las posibilidades por las que un potencial telespectador puede acceder a los contenidos, variando radicalmente el modelo de consumo audiovisual.

La restructuración de las entidades emisoras y su adecuación al nuevo mapa televisivo implica "la aparición de nuevos contenidos, servicios y accesibilidad libre o restringida» con todos los riesgos que esto implica (Francés i Domènec, 2009: 275), pero aunque el modelo televisivo haya cambiado, la televisión generalista financiada primordialmente por la publicidad continua siendo el referente central de ocio para un gran porcentaje de la población (Álvarez Monzoncillo, 2011:93). Las antiguas rutinas son sustituidas por nuevas sinergias, debido entre otras causas, a la penetración expansiva de nuevos hábitos económicos. Mientras las nuevas tecnologías digitales están desplazando a los sistemas mecánicos y electrónicos tradicionales, «la producción en stock desaparece y se fabrican muchos productos bajo demanda, la producción a gran escala es sustituida por las ediciones reducidas», personalizándose el consumo con una mayor flexibilidad de las empresas. La digitalización ha obligado a una nueva manera de relacionarse dimensionándose las empresas hacia un funcionamiento más horizontal (Francés i Domènec, 2009: 278). Pero, según Álvarez Monzoncillo (2011), esta convergencia no siempre resulta tan perfectamente realizable como pueda pensarse, ya que la contradicción inherente entre empresas analógicas y digitales parece llevarnos a un funcionamiento incompatible entre ambas. En ocasiones la contradicción es simplemente aparente aun- 
que en otros resulta más grave. Aunque Internet sea una creciente fuente de ingresos para numerosas empresas, para otras se erige en una amenaza real de sustracción de los ingresos potenciales. Así, mientras que para las entidades productoras de contenidos, Internet continúa viéndose como un peligro, para las televisiones generalistas, cuya financiación proviene esencialmente de la publicidad, se trata de una oportunidad real. Se han ido creando paralelamente, similares barreras de entrada en los mercados digitales a las ya existentes en la economía analógica, produciéndose una progresiva concentración empresarial que pone en duda la competencia en muchos negocios y el mantenimiento de un pluralismo real.

En la carrera entre la innovación técnica y el marco legal, éste siempre permanece detrás. De ahí la gran importancia de contar con una legislación que asuma la variabilidad tecnológica del sector, y que no se quede obsoleta regulando en función de complejas especificaciones técnicas que van a ir mutando con extrema rapidez.

\subsection{La Ley General de Comunicación Audiovisual y el menor}

La Ley General de Comunicación Audiovisual recoge en su preámbulo el objetivo de configurar «un régimen básico común que garantice el pluralismo y los derechos de los consumidores» en una época en la que los modelos de negocio evolucionan en un ámbito en el que se incrementa el acceso a los medios audiovisuales, multiplicándose y fragmentándose las audiencias. De igual forma la norma busca dotar de seguridad a las empresas participantes en un sector, tan amplio como dependiente del desarrollo tecnológico. El capítulo I del Título II busca «la adecuación de los contenidos al ordenamiento constitucional vigente» tratando específicamente las obligaciones que deben mantener los prestadores de servicios de comunicación audiovisual respecto de los menores. Dichos prestadores de servicios están definidos como las personas físicas o jurídicas que tienen la dirección editorial, y por ende el control efectivo, «sobre la selección de los programas y contenidos y su organización en un canal o en un catálogo de programas» entendiendo estos como el "conjunto de programas puestos a disposición del público, que elige el programa y el momento de su visión o su audición». Esta ley reconoce, sin embargo, que «la responsabilidad editorial no implica necesariamente una responsabilidad legal de acuerdo con la legislación nacional por los contenidos o los servicios prestados».

Entre los derechos que se le reconocen al público en el articulado de la ley, están el de recibir una comunicación audiovisual plural, a la diversidad cultural y lingüística, a una comunicación audiovisual transparente, el re- 
conocimiento de los derechos de las personas con discapacidad, así como el derecho a participar en el control de los contenidos audiovisuales. Junto a ellos, el artículo 7 recoge específicamente los derechos propios de los menores, tocando dos aspectos esenciales. El primero corresponde al uso de la imagen y los datos de los menores, mientras que el segundo hace hincapié en las características de los contenidos audiovisuales y cómo estas pueden afectar al desarrollo de los menores. El punto 2 del artículo 7 define específicamente que «está prohibida la emisión de contenidos audiovisuales que puedan perjudicar seriamente el desarrollo físico, mental o moral de los menores, y, en particular, la de aquellos programas que incluyan escenas de pornografía, maltrato, violencia de género o violencia gratuita». Es remarcable que en la primera redacción del texto no se incluían los conceptos de maltrato y violencia de género, aspectos que fueron incluidos en la modificación sobre la norma original aplicada mediante la Ley 7/2010, de 31 de marzo.

Se establecen diversos tramos horarios que definen el grado de protección que debe aplicarse. Así, contenidos potencialmente perjudiciales para el desarrollo físico, mental o moral de los menores únicamente pueden emitirse en abierto entre las 22 y las 6 horas, precedidos siempre por un aviso acústico y visual que les identifique y manteniéndose el indicador visual durante todo el programa. El matiz de aplicarse esta norma a contenidos emitidos en abierto implica que, en un sistema televisivo cada vez más fragmentado y más a la carta deban cubrirse los nuevos modelos de consumo en los que se llega a los programas mediante sistemas de acceso condicional. Por ello deben ser incorporados métodos de control parental por los prestadores del servicio de comunicación audiovisual. La segmentación de las horas de emisión delimita una serie de franjas denominadas de protección reforzada, dos en las jornadas laborables, entre las 8 y las 9 horas y entre las 17 y las 20 horas, y una tercera, entre las 9 y las 12 horas, los sábados, domingos y festivos a nivel estatal.

No son únicamente los programas, sino también las comunicaciones comerciales que se insertan en ellos, las que deben cumplir con la normativa. El concepto de comunicación comercial se aplica a las «imágenes o sonidos destinados a promocionar» directa o indirectamente la imagen, bienes o servicios de una entidad dedicada a una actividad económica, a cambio de una contraprestación para el prestador del servicio, incluyendo formas diversas como el mensaje publicitario, el patrocinio, la televenta y el emplazamiento de producto. En horario de protección al menor, no podrán insertarse comunicaciones comerciales «que promuevan el culto al cuerpo y el rechazo a la autoimagen, tales como productos adelgazantes, intervenciones quirúrgicas o tratamientos de estética, que apelen al rechazo social por la condición física, o al éxito debido a factores de peso o esté- 
tica». De igual manera estas comunicaciones no deben causar ningún perjuicio moral o físico a los menores.

\subsection{El Código de Autorregulación de Contenidos Televisivos e Infancia}

Junto a la segmentación por franjas horarias, es preciso delimitar los tramos por edades a los que se aplica el texto del artículo para poder establecer la idoneidad de los contenidos. La gradación de la calificación deberá homologarse por el Código de Autorregulación de Contenidos Televisivos e Infancia, siendo responsabilidad de la autoridad audiovisual competente «la vigilancia, control y sanción de la adecuada calificación de los programas por parte de los prestadores del servicio de comunicación audiovisual televisiva».

El Código fue una iniciativa que pusieron en marcha en 2005 los operadores televisivos que emiten en abierto, con el objetivo esencial de la defensa y protección de los menores ante el acceso a contenidos que pudieran considerarse inadecuados. Las entidades televisivas que lo promovieron componen el Comité de Autorregulación (CRTVE, Mediaset España, Net TV, Veo TV, FORTA, y Atresmedia), el cual se encarga de emitir los dictámenes sobre las quejas y reclamaciones que los espectadores presentan. El derecho a la participación en el proceso de control de los contenidos le es reconocido a cualquier persona física o jurídica mediante el artículo 9 de la Ley General de Comunicación Audiovisual según el cual puede solicitarse a la autoridad audiovisual competente «el control de la adecuación de los contenidos audiovisuales con el ordenamiento vigente o los códigos de autorregulación». Este proceso se tramita a través de la web www.tvinfancia.es mediante la formulación de una reclamación, en la que aparte de los datos del reclamante, deben cumplimentarse tanto el objeto como el motivo de la queja. El objeto incluye el tipo de contenido (programa, avance de programación o mensaje publicitario), la información sobre el programa o marca de la que se trata y el minuto en el que presuntamente se ha detectado la infracción. El motivo se divide en cuatro posibilidades: comportamiento social, violencia, temática conflictiva o sexo.

Dicha web ha sido promovida por la Comisión Mixta de Seguimiento del Código de Autorregulación formada por las entidades televisivas firmantes del Código, así como por las organizaciones sociales siguientes:

- Consejo de Consumidores y Usuarios (CCU)

- Confederación Española de Asociaciones de Padres y Madres de Alumnos (CEAPA) 
—Confederación Católica de Asociaciones de Padres de Alumnos y Padres de Familia (CONCAPA)

- Plataforma de Infancia

- Federación de Asociaciones de Consumidores y Usuarios de los Medios (ICMEDIA)

La Subdirección de Audiovisual de la Comisión Nacional de Mercados y Competencia es la encargada de emitir los dictámenes que resuelven las infracciones estableciendo las sanciones correspondientes sobre las entidades infractoras.

El Código de Autorregulación establece los principios rectores que deben seguirse en la programación de los contenidos televisivos, no impidiendo que cada televisión siga su propia línea editorial o que incluso incremente el rigor con el que se tratan corporativamente los aspectos relacionados con la infancia. En él, se recogen cuestiones reguladas previamente por diversos textos legales sobre la protección al menor, la salud y la publicidad entre otras, aunque hay que incidir en que la Ley General de Comunicación Audiovisual de 2010, es decir posterior al 2005 en el que se crea el Código y también aglutina en su redacción aspectos previamente dispersos. Establece una serie de principios generales aplicables a la programación emitida en la franja horaria de protección al menor (no reforzada), delimitada entre las 6:00 y las 22:00. Se distinguen los conceptos de público infantil respecto del juvenil, contemplando unos tramos de protección reforzada para el primero, entendido como tal al colectivo de menores de doce años, en la que las televisiones se comprometen a evitar la emisión de contenidos considerables como inadecuados.

En el Código se recoge la responsabilidad prioritaria de los progenitores de los menores, aunque se muestra el compromiso de dotar a los mismos de los instrumentos necesarios para que puedan ejercer dicha responsabilidad mediante la dotación y mejora de los sistemas de calificación y señalización de los contenidos por edades. Para ello se siguieron los criterios existentes en el Instituto de las Ciencias y Artes Audiovisuales (ICAA), dependiente del Ministerio de Cultura en el momento de formalización del Código. Los principios con los que se opera diferencian el horario protegido definido por el tramo de 6:00 a 22:00 del de protección reforzada. En el segundo se distingue entre el público juvenil y el infantil, definiendo al último como el compuesto por los menores de 12 ańos (siguiendo el criterio del ICAA). Ambos colectivos están protegidos dentro de la franja horaria general, incidiendo en los menores en el tramo reforzado debido a la posibilidad existente de que en el mismo puedan no estar apoyados por la presencia de los adultos.

Estos principios recogen, entre otras, las cuestiones siguientes: 
- Garantizar que los derechos fundamentales de los menores participantes sean respetados.

- Incentivar el uso del control parental.

- La colaboración en la correcta alfabetización de los niños, evitando el uso de lenguaje indecente o insultante.

- Impedir que los menores sean incitados a imitar comportamientos perjudiciales o peligrosos para la salud, en especial cuando se trate del consumo de cualquier tipo de droga o del culto a una delgadez extrema.

- Evitar el tratamiento como espectáculo de conflictos personales y familiares.

- Obviar el uso de situaciones que muestren o aludan a un explícito contenido violento o sexual, tanto en los programas destinados al público infantil, como en la publicidad que se inserte en los mismos.

- Incentivar la labor orientadora de los presentadores de los programas en directo, a fin de que adviertan de las situaciones que presumiblemente puedan afectar a la protección de los menores.

- Impedir las demostraciones de ciencias ocultas o de culto a las sectas.

Otros aspectos recogidos en el Código hacen referencia a la presencia de los menores en la programación televisiva, impidiendo la emisión de imágenes que les sitúen como autores, testigos o víctimas de actos ilícitos, evitando el uso de su imagen con menoscabo de su dignidad en los casos en que sufran incapacidades o patologías graves, prohibiendo mostrar a menores identificados consumiendo alcohol, tabaco o sustancias estupefacientes. De igual forma no se realizarán entrevistas a menores identificados como sujetos de situaciones de crisis, ni su participación en aquellos programas en los que se discuta sobre la tutela legal de los mismos ni, finalmente, se permitirá el uso de menores imitando comportamientos vejatorios de sujetos adultos. En cuanto a los programas informativos, y su posible visionado por los menores, se evitarán las imágenes innecesarias para la explicación de la noticia que muestren situaciones violentas, sexo, tratos vejatorios, así como contenidos especialmente crudos o brutales. En cualquier caso, y cuando la relevancia informativa lo justifique, deberá avisarse a los telespectadores de la inadecuación de las imágenes para el público infantil.

Todos los productos audiovisuales distribuidos a través de la televisión deben disponer de una calificación por edades, de acuerdo con las instrucciones sobre su gradación que dicte el Consejo Estatal de Medios Audiovisuales, aunque en estos momentos, el calificador deberá poner a 
disposición del órgano que actualmente cumple esta función, la Comisión Nacional de los Mercados y la Competencia (CNMC), la ficha que justifique su decisión. Dicha ficha de calificación estudiará tres componentes: la definición del contenido, los elementos positivos para la infancia y los aspectos negativos que pueda contener cada programa evaluado. Se dictaminará si se trata de un contenido de ficción o de no ficción, estableciendo el género al que pueda pertenecer en el primero de los casos (comedia, drama, bélico, etc.) y si se trata de un programa grabado o en directo en el caso de tratarse de no ficción. Los informativos se excluyen de calificación aunque se mantiene la advertencia verbal necesaria para los casos en los que se muestren imágenes inadecuadas para el menor. Las retransmisiones de acontecimientos diversos (deportivos, culturales, políticos o musicales entre otros) no están obligados a ser calificados salvo que se requiera una calificación específica (boxeo, lucha...). Los elementos positivos para la infancia serán definidos así como los negativos. En este caso se tratarán aspectos como la violencia, sexo, miedo o angustia, drogas y sustancias tóxicas, discriminación, conductas imitables, lenguaje (escrito, verbal o gestual) en función de tres posibilidades. Si la conducta o situación se ve en la pantalla (presencia), si se alude a ellas de manera verbal o gestual (presentación), o si por su intensidad, frecuencia o significación no pueden considerarse el núcleo principal del programa (presencia o presentación accesoria).

La decisión final del evaluador calificará el programa como perteneciente a uno de estos grupos:

—Especialmente recomendado para la infancia.

- Para todos los públicos.

- Para mayores de siete años.

- Para mayores de doce ańos.

- Para mayores de dieciséis años.

- Para mayores de dieciocho años.

La calificación por edades proveniente de la ficha será la primera característica que decida la posible ubicación horaria del programa, mientras que el cumplimiento de las condiciones de la misma definirá la resolución de la posible reclamación que se efectúe sobre el contenido.

\section{Análisis empírico}

\subsection{Responsabilidad Social Corporativa}

Como paso previo a nuestro análisis empírico, consideramos interesante, aunque sea brevemente, referenciar al menos un trabajo realizado en 
España relacionado con nuestro trabajo. Así Delgado y Olarte (2012) realizan un análisis de los informes de responsabilidad social de las empresas del sector televisivo durante el periodo 2007-2009. Este trabajo, al igual que esta investigación, está fundamentado en la capacidad de las televisiones para generar y modificar opiniones y/o comportamientos a través de sus audiencias, junto a la falta de análisis del desempeńo de responsabilidad social en el sector de la televisión en Espańa. Nuestro trabajo particulariza aún más el campo de estudio, al centrarse básicamente en la protección a la infancia y la responsabilidad social de los grupos de comunicación en base a la programación televisiva y en concreto la que tiene lugar en la franja de especial protección. En las fechas del trabajo analizado se estudiaron las cinco cadenas generalistas principales, mientras que en nuestro estudio, fruto de procesos de restructuración empresarial, analizaremos los dos grandes grupos audiovisuales existentes en la actualidad.

Dentro de las conclusiones del trabajo de Delgado y Olarte (2012) podemos destacar que el primer informe publicado sobre RSC de Telecinco es del año 2005 mientras que Antena 3 realiza en 2007 su primer informe de Responsabilidad Corporativa. Ambos utilizan la Guía Global Reporting Iniciative, aunque inicialmente en ninguno de ellos consta con verificación externa. Posteriormente tanto en Antena 3 como en Telecinco consta su incorporación al índice FTSE4Good Ibex y su adhesión al Pacto Mundial de Naciones Unidas; siendo su memorias ya verificadas externamente con la máxima calificación.

Una vez analizado el trabajo de Delgado y Olate (2012), que toma como última referencia el ejercicio 2009, a continuación mostramos los datos más relevantes obtenidos de las propias páginas web de los dos grupos audiovisuales, obtenidos en el mes de Julio de 2016.

MEDIASET incluye la información relacionada con responsabilidad social corporativa a través de dos accesos dentro del menú «relación con Inversores» $\mathrm{y}$ «mediaset.com». En «relación con inversores» a través de dos submenús «gobierno corporativo» y «responsabilidad corporativa». Mientras que en "mediaset.com» dentro del submenú «información corporativa». Por otra parte, también destacamos otro menú «12 meses», dentro del cual aparece la campańa activa del grupo "12 meses 12 causas», como diseño de campañas de concienciación (Campaña que ha cumplido 12 años, y dentro de la cual, entre otros aspectos, se ha apoyado a los niños)

Dentro de «relación con inversores / gobierno corporativo» destacamos «el informe anual de gobierno corporativo» referido al ejercicio 2015, dentro del cual queremos destacar el siguiente hecho, que consideramos relevante para juzgar la realidad de la responsabilidad social de la compañía. En el punto 54 referido a la RSC, sólo cumple las recomendaciones parcialmente, al no tener aprobada una política expresa en esta materia. 
En «relación con inversores / gobierno corporativo» señalamos «el informe anual sobre remuneraciones de los consejeros» referido al ejercicio 2015. La remuneración total en metálico del consejo de administración asciende a 5,4 millones de euros para 13 consejeros, 3 de los cuales son consejeros ejecutivos. La remuneración total de la alta dirección asciende a 7,5 millones de euros para 21 personas.

Dentro de «relación con inversores / responsabilidad corporativa» podemos destacar «el informe de responsabilidad corporativa 2015», dentro del cual queremos destacar el siguiente hecho en palabras del presidente "...Por otra parte, nuestra gestión ética, transparente, sostenible y solidaria, con politicas que han impulsado la emisión responsable de contenidos y de publicidad, han vuelto a ser las guias que han marcado la relación con nuestros empleados, proveedores, clientes e instituciones del sector, en definitiva, nuestro COMPROMISO para con quienes desarrollamos los distintos procesos que confluyen en los resultados que les he resumido en estas lineas...». Dentro de los grupos de interés, no figura expresamente nada relacionado con los menores de edad dentro de la audiencia. Únicamente resume su valoración para la sociedad con el proyecto «12 meses» dejando sin más efecto su COMPROMISO

En la «relación con inversores / responsabilidad corporativa» podemos señalar «la información económica» del ejercicio 2015, destacando que los 167 millones de beneficios del ejercicio 2015 se distribuyen vía dividendos. Los sueldos y salarios del personal ascienden a 68 millones para 1.008 empleados. Una mera operación aritmética nos lleva a que la remuneración media anual por consejero asciende a algo más de 400.000 mil euros; la remuneración media anual por alto directivo asciende a poco más de 350.000 euros; y el sueldo medio anual por empleado asciende a casi 70.000 euros.

Por último destacar, el enlace a través de mediaset.com con «12 meses» "... parte de su espacio publicitario y el foco de sus contenidos a sensibilizar a los espectadores sobre asuntos cruciales para la sociedad desde un punto de vista solidario, con el convencimiento de que la actitud individual, familiar y colectiva es clave en la contribución a la mejora de determinadas situaciones».

ATRESMEDIA incluye la información relacionada con responsabilidad social corporativa a través de tres accesos dentro del menú «fundación atresmedia», «responsabilidad corporativa» e «información corporativa y financiera». En "fundación atresmedia» incluyendo los proyectos activos de la fundación. En «responsabilidad corporativa» incluye las campañas activas del grupo. Mientras que en «información corporativa y financiera», dentro del submenú «atresmedia» incorpora «RC». 
En Fundación Atresmedia, dentro de los fines podemos encontrar los que sustentan el objeto de nuestro trabajo: «proteger a la infancia y primera juventud, mediante la defensa de sus derechos, necesidades e intereses» "contribuir en la mejora y enriquecimiento de la relación entre los menores y el medio televisivo, de modo que éste sea una herramienta de comunicación al servicio de su desarrollo personal y cívico». Por otra parte dentro de los proyectos de la Fundación, también destacamos el que lleva por título «mejora educativa» por su especial relación con la infancia. Dentro de las normas de buen gobierno, nos llama la atención, al hablar de «recursos económicos de la fundación» que se ponga un límite superior a la aportación de Atresmedia a su fundación, concretamente «la dotación no superará el 0,7\% del beneficio consolidado antes de impuestos del ejercicio anterior».

En el menú «RC» destacamos dentro de los «informes» un enlace directo con protección a la infancia, Para velar por la protección de los menores en los contenidos, Atresmedia está adherido desde 2005 al Código de Autorregulación sobre Contenidos Televisivos e Infancia. Destacando en su web, que en 2015 el Comité de Autorregulación no ha aceptado ninguna reclamación formulada, mejorando los datos del ejercicio 2014.

Dentro de «RC» señalamos «el informe anual de gobierno corporativo» referido al ejercicio 2015, dentro del cual queremos destacar el siguiente hecho, ya que en comparación con MEDIASET, sí cumple íntegramente el punto 54 referido a la RSC.

En «RC» destacamos «el informe anual sobre remuneraciones de los consejeros» referido al ejercicio 2015. La remuneración total en metálico del consejo de administración asciende a 5 millones de euros para 12 consejeros, 2 de los cuales son consejeros ejecutivos. La remuneración total de la alta dirección asciende a 5,5 millones de euros para 12 personas.

Dentro de «RC" podemos destacar las cuentas anuales del ejercicio 2015, destacando que los 90 millones de beneficios del ejercicio 2015 prácticamente en su totalidad se distribuyen vía dividendos. Los sueldos y salarios del personal ascienden a 38 millones para 435 empleados. Una mera operación aritmética nos lleva a que la remuneración media anual por consejero asciende a algo más de 400.000 mil euros; la remuneración media anual por alto directivo asciende a poco más de 450.000 euros; y el sueldo medio anual por empleado asciende a casi 90.000 euros.

Nos llama la atención, la duplicidad en la terminología RC - Responsabilidad Corporativa, que puede generar confusión, ya que de hecho los contenidos de «responsabilidad corporativa» son meramente las campańas de sensibilización, dejando para un submenú el contenido básico de la RC.

Por otra parte, a continuación procedemos a desarrollar el esquema principal del análisis empírico realizado y particularizado a la protección a la infancia. 


\subsection{Metodología de análisis de los informes de la Comisión}

La Comisión Mixta de Seguimiento del Código de Autorregulación sobre Contenidos Televisivos e Infancia ha confeccionado 10 informes en los que han ido reflejándose las resoluciones tomadas sobre las reclamaciones formuladas a través de la web www.tvinfancia.es. Las mismas se refieren a contenidos y programas difundidos por las cadenas firmantes del Código en horario de protección al menor (de las 6:00 de la mañana a las 22:00 de la noche), incidiendo especialmente en las franjas de protección reforzada.

El primer informe se efectuó sobre el periodo comprendido entre marzo de 2005 y marzo de 2006, continuando los siguientes con el mismo esquema de trabajo.

Sobre las reclamaciones:

Hasta 2014, los contenidos reclamados se evaluaban en función de cuatro grandes áreas:

- Comportamiento social

- Temática conflictiva

- Violencia

-Sexo

Desde el último informe, emitido en 2015, y debido a la reforma de los criterios por los que se califican, los contenidos sobre los que se presente alguna reclamación, estos serán evaluados desde las siguientes perspectivas:

-Violencia

- Sexo

- Miedo o angustia

-Drogas y sustancias tóxicas

- Discriminación

- Conductas imitables

- Lenguaje

De igual forma, debe reseñarse que de la calificación por edades inicial, en la que se usaba la clasificación para mayores de 13 años como instrumento para categorizar los programas se ha pasado a la actual categoría de «para mayores de 12 ańos».

La metodología empleada ha sido la siguiente: Se ha tomando como base de trabajo los 10 informes realizados hasta la fecha por la Comisión Mixta de Seguimiento del Código de Autorregulación sobre Contenidos Televisivos e Infancia, de los años 2006 al 2015, aplicando el aná- 
lisis a los datos allí reflejados sobre las reclamaciones efectuadas y sobre las efectivamente aceptadas, que tuviesen como objeto los contenidos y programas de las cadenas que actualmente pertenecen a los grupos Atresmedia y Mediaset. Hay que señalar que la irrupción y definitiva instauración de la Televisión Digital Terrestre (TDT) provocó la aparición de nuevos canales que han operado bajo las licencias otorgadas a las cadenas Antena 3 y Telecinco (Mediaset) En el primer caso nos referimos a Neox y Nitro, mientras que en el segundo podemos actualmente incluir FDF, Boing, Energy, Divinity y en su momento La Siete. De igual forma, y como faculta la Ley General de Comunicación Audiovisual, se ha facilitado el proceso de integración empresarial entre cadenas distintas, siempre que, como informa el artículo 36 de dicha ley, la audiencia media de las mismas no supere el $27 \%$ del total posible durante los doce meses anteriores al proceso de adquisición. Esto permitió que Telecinco y Cuatro se integrasen a comienzos de 2011, sucediendo lo mismo con Antena 3 y La Sexta durante 2012. Por ello, tanto Cuatro como La Sexta han sido incluidas en el análisis aunque no formasen parte como tal de Mediaset y Atresmedia respectivamente al comienzo de la realización de los informes.

Los elementos analizados han sido tanto las reclamaciones presentadas y por ello evaluadas en cada una de las cadenas, así como las aceptadas. En estas últimas, el objeto de análisis ha sido el motivo por el que han sido tomadas en cuenta por parte de la Comisión, unificando los mismos en áreas temáticas similares contempladas por el mismo Código (sexo, violencia, comportamiento social, temática conflictiva) así como en otras que están presentes con regularidad en la explicación de los motivos que han definido la decisión tomada (lenguaje, clasificación para mayores de 18 años, clasificación para mayores de 13 años y «otros», que incluyen otras motivaciones diversas. La inserción en la redacción del motivo de vocablos como «sexual» o "violentas», ha definido su inclusión en las áreas temáticas de «sexo» $\mathrm{y}$ "violencia» respectivamente.

\subsection{Análisis}

Tras la realización del análisis de las reclamaciones efectuadas a través de la web www.tvinfancia.es y presentes en los 10 informes emitidos, enunciando una queja sobre el posible incumplimiento de las premisas de Código de Autorregulación de Contenidos Televisivos e Infancia se ha establecido una primera tabla comparativa que recoge, desglosada por ańos y cadenas, los datos de las reclamaciones recibidas y las efectivamente aceptadas como punibles por parte de la Comisión. 


\section{Tabla 1}

Elaboración propia

\begin{tabular}{|c|c|c|c|c|c|c|c|c|c|c|c|c|c|}
\hline & & & 2015 & 2014 & 2013 & 2012 & 2011 & 2010 & 2009 & 2008 & 2007 & 2006 & Total \\
\hline \multirow{16}{*}{ 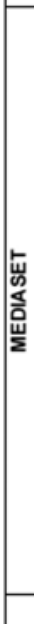 } & Telecinco & Recibidas & 42 & 54 & 12 & 40 & 118 & 40 & 25 & 28 & 46 & 66 & 471 \\
\hline & & Aceptadas & 7 & 17 & 3 & 4 & 14 & 7 & 9 & 15 & 4 & 6 & 86 \\
\hline & Cuatro & Recibidas & 42 & 24 & 2 & 1 & 13 & 22 & 13 & 30 & 71 & 9 & 227 \\
\hline & & Aceptadas & 1 & 3 & 1 & 0 & 0 & 5 & 6 & 7 & 12 & 0 & 35 \\
\hline & FDF & Recibidas & 10 & 9 & 3 & & & & & & & & 22 \\
\hline & & Aceptadas & 1 & 0 & 0 & & & & & & & & 1 \\
\hline & Boing & Recibidas & 4 & 6 & & & & & & & & & 10 \\
\hline & & Aceptadas & 0 & 0 & & & & & & & & & 0 \\
\hline & Energy & Recibidas & 1 & 1 & & & & & & & & & 2 \\
\hline & & Aceptadas & 0 & 0 & & & & & & & & & 0 \\
\hline & Divinity & Recibidas & 1 & 1 & 2 & & & & & & & & 4 \\
\hline & & Aceptadas & 0 & 0 & 0 & & & & & & & & 0 \\
\hline & La siete & Recibidas & & & 1 & 2 & & & & & & & 3 \\
\hline & & Aceptadas & & & 1 & 0 & & & & & & & 1 \\
\hline & MEDIASET & Recibidas & 100 & 95 & 20 & 43 & 131 & 62 & 38 & 58 & 117 & 75 & 739 \\
\hline & & Aceptadas & 9 & 20 & 5 & 4 & 14 & 12 & 15 & 22 & 16 & 6 & 123 \\
\hline \multirow{12}{*}{ 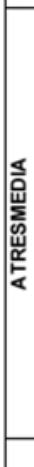 } & Antena 3 & Recibidas & 18 & 18 & 7 & 13 & 30 & 27 & 45 & 94 & 209 & 43 & 504 \\
\hline & & Aceptadas & 1 & 5 & 0 & 2 & 2 & 7 & 9 & 11 & 12 & 6 & 55 \\
\hline & La sexta & Recibidas & 8 & 6 & 3 & 3 & 9 & 32 & 27 & 52 & 18 & & 158 \\
\hline & & Aceptadas & 1 & 0 & 0 & 0 & 1 & 3 & 11 & 38 & 2 & & 56 \\
\hline & Neox & Recibidas & 9 & & 3 & 7 & & & & & & & 19 \\
\hline & & Aceptadas & 0 & & 0 & 0 & & & & & & & 0 \\
\hline & Nitro & Recibidas & & 3 & & & & & & & & & 3 \\
\hline & & Aceptadas & & 3 & & & & & & & & & 3 \\
\hline & La sexta 3 & Recibidas & & & 1 & 1 & & & & & & & 2 \\
\hline & & Aceptadas & & & 0 & 0 & & & & & & & 0 \\
\hline & ATRESMEDIA & Recibidas & 35 & 27 & 14 & 24 & 39 & 59 & 72 & 146 & 227 & 43 & 686 \\
\hline & & Aceptadas & 2 & 8 & 0 & 2 & 3 & 10 & 20 & 49 & 14 & 6 & 114 \\
\hline
\end{tabular}

En una segunda tabla se presentan los datos de los programas sobre los que se han presentado un mayor número de quejas por parte de los telespectadores, a través de la página www.tvinfancia.es. Estos programas son o han sido emitidos, total o parcialmente, en las franjas horarias definidas como de protección reforzada. Los programas se han agrupado según el tipo de contenido estableciendo las siguientes categorías: magacines, programas humorísticos, informativos vespertinos, series de ficción y programas infantiles. 
Tabla 2

Elaboración propia

\begin{tabular}{|c|c|c|c|c|c|c|c|c|c|c|c|c|}
\hline & & $\frac{\varpi}{5}$ & 훙 & $\frac{m}{0}$ & 뚱 & $\overline{0}$ & 응 & 8 & 8 & 8 & 8 & Bubtotal \\
\hline \multicolumn{13}{|c|}{ Magaolnec } \\
\hline Telecinco & aslvame & 20 & 38 & 6 & 40 & 116 & 26 & & & & & 245 \\
\hline Telecinco & Aquil hay tomate & & & & & & & & & & 14 & 14 \\
\hline Telecinco & A tu lado & & & & & & & & & 35 & 44 & 79 \\
\hline Telecinco & Exts pasando & & & & & & & 9 & & & & 9 \\
\hline Cugtro & Charnel ne4 & & & & & & & & 11 & 45 & 8 & 65 \\
\hline Antena 3 & El dario de Patricia & & & & & & & & 10 & & 10 & 20 \\
\hline Antena 3 & El dario (de) & & & & 13 & 16 & 5 & 6 & & & & 40 \\
\hline Antena 3 & Tal cual (lo contamos) & & & & & 4 & 9 & 11 & & & & 24 \\
\hline Antens 3 & La buens onda & & & & & & & & & & 24 & 24 \\
\hline \multicolumn{13}{|c|}{ Proeramac humorictloos } \\
\hline Cuatro & Tonterias las Justas & & & & 1 & 7 & & & & & & 8 \\
\hline La zexta & Zapeando & 2 & & & & & & & & & & 2 \\
\hline La gexta & 3e lo que hiciatela & & & & 1 & 4 & & 6 & & & & 11 \\
\hline \multicolumn{13}{|c|}{ Informativoc vecpertinoc } \\
\hline Cuatro & Vato y oido & & & & & & & 2 & & & & 2 \\
\hline La sexta & Mas vale tarde & & 1 & 1 & & & & & & & & 2 \\
\hline \multicolumn{13}{|c|}{ seriec do floolon } \\
\hline FDF & La que ae avecing & 4 & 5 & 1 & & & & & & & & 10 \\
\hline FDF & Nda & 3 & 1 & & & & & & & & & 4 \\
\hline Antens 3 & El secreto de puente viejo & 9 & 2 & & & & & & & & & 11 \\
\hline Antens 3 & Pasion de gavilanes & & & & & & & & & & 3 & 3 \\
\hline La sexta & Que vida mas triate & & & & & 3 & 10 & & & & & 13 \\
\hline Neox & Dos hombres y medo & & & 2 & 1 & 3 & & & & & & 6 \\
\hline Nitro & Calfomication & & 3 & & & & & & & & & 3 \\
\hline \multicolumn{13}{|c|}{ Programac Infontlles } \\
\hline La giete & Oouth Park & & & & 1 & & & & & & & 1 \\
\hline Cuatro & Bola de dropon Z & & & & & & & 2 & & & & 2 \\
\hline Boing & Doraemon & 1 & 2 & & & & & & & & & 3 \\
\hline Neox & Shin Chan & & & & 6 & & & & 49 & 121 & 1 & 177 \\
\hline Neox & Padre de famlla & & & 1 & & & & & & & & 1 \\
\hline
\end{tabular}


Tabla 3

Elaboración propia

\begin{tabular}{|c|c|c|c|c|c|c|c|c|c|c|c|c|}
\hline $\begin{array}{l}\text { Reclamaciones aceptadas en } \\
\text { función del término empleado en } \\
\text { el motivo }\end{array}$ & & $\frac{\infty}{2}$ & $\frac{\pi}{8}$ & $\frac{m}{8}$ & $\frac{2}{2}$ & $\overline{8}$ & 을 & 要 & : & \&े & ๕ & 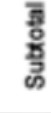 \\
\hline & TOTAL & & & & & & & & & & & 283 \\
\hline \multirow[t]{7}{*}{ SEXO(sexual) } & Telecinco & & 4 & 3 & 1 & 4 & 3 & 1 & 1 & & & 17 \\
\hline & Cuatro & & 2 & 1 & & & & & 1 & 3 & & 7 \\
\hline & FDF & 1 & & & & & & & & & & 1 \\
\hline & La Siete & & & 1 & & & & & & & & 1 \\
\hline & Antena 3 & & 4 & & & & 1 & & & 2 & & 7 \\
\hline & La sexta & & & & & 1 & & 1 & 3 & & & 5 \\
\hline & Nitro & & 3 & & & & & & & & & 3 \\
\hline \multirow{4}{*}{ VOLENCLA (violentas) } & Telecinco & & 2 & & 2 & 1 & 1 & & 3 & 1 & & 10 \\
\hline & Cuatro & 1 & 1 & & & & & & 2 & 1 & & 5 \\
\hline & Antena 3 & & & & & & 4 & 2 & 3 & & & 8 \\
\hline & La sexta & 1 & & & & 1 & & 1 & & & & 3 \\
\hline \multirow[t]{4}{*}{ COMAPORTAMIENTO SOCLAL } & Telecinco & & & & 2 & 11 & 3 & 1 & 4 & & & 21 \\
\hline & Cuatro & & & & & & & & 1 & & & 1 \\
\hline & Antena 3 & & & & & & 1 & 1 & 3 & & & 5 \\
\hline & La sexta & & & & & 1 & 1 & 2 & 9 & & & 13 \\
\hline \multirow{4}{*}{$\begin{array}{l}\text { TEMATICA CONFLICTIVA } \\
\end{array}$} & Telecinco & & & & 3 & 2 & 1 & & 4 & 2 & & 12 \\
\hline & Cuatro & & & & & & & & 1 & & & 1 \\
\hline & Antena 3 & & & & 2 & 1 & 2 & & 7 & 3 & & 15 \\
\hline & La sexta & & & & & 1 & & 2 & & & & 3 \\
\hline \multirow[t]{3}{*}{ LENGUANE } & Telecinco & & 1 & & & & & & & & 2 & 3 \\
\hline & Cuatro & & & & & & & & & 2 & & 2 \\
\hline & Antena 3 & & & & & & & & & & 2 & 2 \\
\hline \multirow[t]{4}{*}{ CLASIFICACION $>18$ ANOS } & Telecinco & & & & & & 2 & 7 & 6 & 1 & & 16 \\
\hline & Cuatro & & & & & & 3 & 8 & 3 & 5 & & 17 \\
\hline & Antena 3 & & & & & & 2 & 7 & 4 & 4 & & 17 \\
\hline & La sexta & & & & & & 2 & 6 & 4 & 1 & & 13 \\
\hline \multirow{5}{*}{ CLASIFICACION $>13$ ANOS } & & & & & & & & & & & & \\
\hline & lelecinco & & & & & & 1 & & 3 & & & 4 \\
\hline & Cuatro & & & & & & 2 & & & & & 2 \\
\hline & Antena 3 & & & & & 1 & & & & & & 1 \\
\hline & La sexta & & & & & & & 2 & 33 & & & 35 \\
\hline \multirow{5}{*}{ OTROS } & & & & & & & & & & & & \\
\hline & Telecinco & 7 & 10 & & & & & & & & 4 & 21 \\
\hline & Cuatro & & & & & & & & & 1 & & 1 \\
\hline & Antena 3 & 1 & 1 & & & & & & & 3 & 4 & 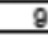 \\
\hline & La sexta & & & & & & & & & 1 & & 1 \\
\hline
\end{tabular}


En la tercera tabla se muestran los motivos esgrimidos por la Comisión, en los casos en que se ha considerado que la reclamación efectuada era correcta. En estos casos, la Comisión define el programa, la cadena que lo ha emitido y la fecha en la que lo ha hecho, así como la tipificación motivada por la que ha tomado su decisión. Para la confección de esta tabla, y por la no uniformidad en cuanto a la forma de enunciar el motivo de la aceptación de la queja a lo largo de los 10 informes, se ha optado por tomar como ítem clasificatorio el de los vocablos empleados por la Comisión en su redacción, asimilándolo a las áreas temáticas que contemplan los informes para la evaluación de los contenidos. Hay que destacar que, al no ser en muchos de los casos un único motivo el tomado en cuenta por la Comisión en su evaluación, en muchos casos se multiplican los términos empleados. Valga como ejemplo el motivo esgrimido para evaluar al programa Sálvame de Telecinco, emitido el 24 de agosto de 2009. En el quinto informe realizado se esgrime como motivo para aceptar la reclamación el de "Comportamiento social, violencia y temática conflictiva». En este caso, en la tabla se ha incluido este dato en cada uno de los tres epígrafes aunque corresponda a una única reclamación recibida y aceptada. El total de motivos aludidos ha sido 283 a lo largo de los 10 informes, sin embargo el total de reclamaciones aceptadas sobre la programación de las entidades televisivas estudiadas fue de 238. Es decir, hubo 45 situaciones aceptadas por motivo múltiple.

\section{Resumen resultados}

En primer lugar, como mera referencia aritmética; no podemos constatar grandes diferencias entre las remuneraciones de los altos directivos y de los consejeros de los dos grupos audiovisuales; siendo incluso la retribución de la alta dirección menor que la retribución media de los miembros de la alta dirección, según consta en el informe de gobierno corporativo de las entidades emisoras de valores admitidos a negociación en mercados secundarios oficiales del ejercicio 2014, que se situó en 973.000 euros frente a los 450.000-500.000 euros de los ejercicios 2011-2013. La retribución de los consejeros sí es ligeramente superior a la retribución media por consejero, según consta en el informe anual de remuneraciones de los consejeros de las sociedades cotizadas del ejercicio 2014, que se sitúo en 318.000 euros anuales.

MEDIASET presenta datos económicos mejores cuantitativamente que los de ATRESMEDIA pero sin embargo no demuestra una mejor RSC que ATRESMEDIA. De hecho, no cumple totalmente con el punto 54 de las recomendaciones del gobierno corporativo y gran parte de «su responsabilidad» está basada en la campaña «12 meses 12 causas». Por el 
contrario ATRESMEDIA, tiene constituida una fundación que entre otros fines recoge la protección a la infancia, que incluso en la propia página web del grupo incluye un enlace directo con protección a la infancia.

Para las siguientes reflexiones tomaremos como base de trabajo los datos correspondientes a las principales cadenas intervinientes en las entidades, es decir, Telecinco y Cuatro en el caso de Mediaset, y Antena 3 y La Sexta para Atresmedia. De los datos de la primera tabla se pueden extraer los siguientes porcentajes en cuanto a reclamaciones aceptadas respecto de las presentadas:

—Mediaset: 16,64\% de reclamaciones aceptadas (123/739). De ellas corresponden a las dos principales cadenas los siguientes ratios:

- Telecinco: $18,25 \%(86 / 471)$

- Cuatro: $15,41 \%(35 / 227)$

- Atresmedia: 16,61\% de reclamaciones aceptadas (114/686). Operando de igual forma, corresponden a las dos principales cadenas los siguientes ratios:

- Antena 3: $10,91 \%(55 / 504)$

- La Sexta: $35,44 \%(56 / 158)$

Se advierte la similitud porcentual entre ambos grupos (insistimos en que los datos recogidos pertenecen también a periodos en que aún no existía un proceso de concentración empresarial), y la desproporción en cuanto a las reclamaciones aceptadas sobre las presentadas por programas emitidos por La Sexta.

El proceso de integración protagonizado por Telecinco y Cuatro, como empresas más reconocibles, tuvo lugar de manera efectiva a principios de 2011, mientras que el de Antena 3 y La Sexta, sucedió durante el último trimestre de 2012, por lo que empiezan a recogerse los datos en el $7 .^{\circ}$ y en el $8 .^{\circ}$ informes respectivamente. Los datos previos a la integración para Telecinco en cuanto al ratio reclamaciones aceptadas respecto de las presentadas es del $17,02 \%(55 / 323)$ mientras que los posteriores son del $20,94 \%(31 / 148)$. En el caso de Cuatro, el ratio anterior a dicho proceso es del 18,98\% (30/158) mientras que después ha pasado al 7,24\% (5/69). Los globales han pasado del 17,67\% (85/481) de Telecinco y Cuatro, antes de la integración al $16,58 \%$ posterior (36/217). En cuanto a Antena 3 y La Sexta, antes de su integración los ratios de aceptación de las reclamaciones eran del 10,62\% (49/461) en la primera y del 39\% (55/141) en la segunda. Tras el proceso integrador de las empresas los ratios fueron para Antena $313,95 \%(6 / 43)$ y del 5,88\% (1/17) para La Sexta. Los datos globales previos son del 17,27\% (104/602) y posteriores del 11,66\% (7/60). Se aprecia la radical variación en el caso de La Sexta. 
La variación de la percepción de infracción que tiene el espectador sobre la legislación protectora al menor puede inferirse del número de reclamaciones efectuadas hasta la integración de las cadenas y después de la misma. Tomando como referencia las cadenas principales (Telecinco, Cuatro, Antena 3 y La Sexta), en el caso de Mediaset 80,16 reclamaciones realizadas anuales antes y 54,25 tras el proceso de integración (69,8 como media anual en el total de los informes generados). En el de Atresmedia son 66,2 reclamaciones efectuadas por año como media a lo largo de los 10 informes, pero antes de la integración dicha media anual es de 86 reclamaciones y después tan solo de 20 . La variación del grado de cumplimiento podría inferirse de las reclamaciones aceptadas cada año por las cadenas principales de Mediaset 14,16 anuales previamente al proceso y 9 por ańo tras el mismo. En el caso de Atresmedia, 14,85 antes de la integración y tan solo 2,33 por año después.

Los posibles efectos de la Ley General de Comunicación Audiovisual de 3 de marzo de 2010, deberían recogerse en el 6. informe. La comparativa se muestra en el siguiente esquema:

-Telecinco:

- Reclamaciones aceptadas/presentadas ( $1 .^{\circ}$ al $5 .^{\circ}$ informes): $41 / 205(20 \%)$

- Reclamaciones aceptadas/presentadas (6. ${ }^{\circ}$ al $10 .^{\circ}$ informes): $45 / 266(16,91 \%)$

-Cuatro:

- Reclamaciones aceptadas/presentadas ( $1 .^{\circ}$ al $5 .^{\circ}$ informes): 30/145 (20,68\%)

- Reclamaciones aceptadas/presentadas (6. ${ }^{\circ}$ al $10 .^{\circ}$ informes): 5/82 $(6,09 \%)$

-Antena 3:

- Reclamaciones aceptadas/presentadas (1.0 al 5.0 informes): 45/418 (10,76\%)

- Reclamaciones aceptadas/presentadas (6. ${ }^{\circ}$ al $10 .^{\circ}$ informes): $10 / 86(11,62 \%)$

- La Sexta:

- Reclamaciones aceptadas/presentadas (1.0 al 5.0 informes): $54 / 129(41,86 \%)$

- Reclamaciones aceptadas/presentadas ( $60^{\circ}$ al $100^{\circ}$ informes): $2 / 29(6,89 \%)$ 
Es decir, La Sexta muestra una clara variación en sus ratios coincidiendo con la llegada de la Ley. Se observa un lapso temporal no cubierto, situado entre el $7 .^{\circ}$ y 8..$^{\circ}$ informes. El primero cubre del 9 de marzo de 2011 a la misma fecha de 2012, mientras que el segundo recoge la información tomada a lo largo de 2013, por lo que los tres últimos trimestres del 2012 no figuran en los informes generados. Existe un salto en cuanto a las reclamaciones aceptadas, que va desde la tomada por el programa «Sálvame» emitido por Telecinco el 27/06/2011 a la que se aceptó sobre la emisión que tuvo lugar el 12/06/2013 de "El programa de Ana Rosa», también de la misma cadena, Telecinco.

En cuanto a los motivos por los que se han aceptado las reclamaciones, el sexo es el término empleado en 26 ocasiones en los canales de Mediaset y 15 veces en el caso de Atresmedia (41 totales), apreciándose menos diferencias entre ambos grupos con el resto de los términos. El vocablo violencia se usa en la redacción del motivo 15 veces para los canales de Mediaset y 12 en los de Atresmedia, comportamiento social, 22 ocasiones frente 18 , temática conflictiva 13 ante 18 , el lenguaje 5 frente a 2, mientras que "otros" motivos son empleados en el dictamen 22 ocasiones en el caso de Mediaset y 10 en Atresmedia.

Es destacable que la indicación de clasificado para mayores de 18 años (33 veces en el caso de Mediaset y 30 para Atresmedia) tiene una cifra similar a la suma de las infracciones reconocidas por la no de adecuación de los contenidos a los menores por los motivos de sexo y violencia, con un total de 68. De igual forma, la indicación de clasificados para mayores de 13 años, tiene datos muy divergentes en el caso de Mediaset (6) frente a los 36 de Atresmedia. Esto puede deberse a unos años en los que se ha procedido a la reemisión en horario de protección reforzada matinal de ciertos programas nocturnos (late night) como Buenafuente, concebidos para un tipo de público potencial muy distinto al infantil (27 reclamaciones aceptadas de las 36 presentadas). Este tipo de situaciones muestran la distancia existente entre el proceso de trabajo propio de la producción del contenido, respecto de la labor desarrollada por los programadores y organizadores de la parrilla televisiva. Como se muestra en la tabla número 2, formatos ideados para un horario nocturno y dirigidos a un público adulto se adecúan a dichas premisas, que no obligan a un seguimiento estricto de la normativa propia de defensa del menor. Al ser emitidos como repetición en una franja de protección reforzada matinal, consecuentemente tienen más riesgo de ser percibidos por los espectadores como infractores de la ley. De igual manera programas de infantiles de dibujos animados como Shin Chan, pueden ser percibidos de igual manera por el tono políticamente incorrecto del personaje protagonista. Pero esto puede ser debido tanto a motivos culturales de los distintos países de producción y emisión 
como quizá, a la intencionalidad que se le quiere otorgar a las acciones del personaje, cuestiones que merecerían un análisis fílmico específico. Lo esencial es que el contenido se adquiere por la empresa televisiva como un producto terminado, y serán las características del mismo las que debieran dirigir el horario de su emisión a una franja u otra.

La franja de protección reforzada vespertina sugiere otras cuestiones a debatir. La presencia de un programa como Sálvame, que actualmente escinde su duración en dos tramos con denominaciones distintas. Un primero llamado «Sálvame Limón» que se anuncia en la guía de programación en el horario de 16:00 a 17:00, fuera de la franja de protección reforzada, y un segundo "Sálvame Naranja» cubriendo íntegramente dicha franja de 17:00 a 20:00. La excusa formal pretende salvar la normativa, presumiblemente dirigiendo temáticas más conflictivas al primer tramo, y las más «suaves» al segundo. Entendemos que admite, cuando menos, discusión la eficacia cara a la protección al menor de esta estrategia, aunque sería un análisis de otro tipo el que podría definir con certeza la cuestión del mayor o menor respeto a la ley del contenido emitido. En el mismo horario vespertino, se repite una circunstancia relacionada con los productos terminados, en este caso, capítulos de series de ficción tanto nacionales como no. Canales como Neox o FDF, recogen en su parrilla producciones muy diversas, destinadas a un público más adulto, y un horario no necesariamente vespertino. Pero este tipo de canales de la TDT, anexos a los principales como Antena 3 o Telecinco por ejemplo, actúan como un cajón de sastre donde caben emisiones muy variadas, pareciendo existir un menor control sobre la temática, situaciones o acciones que los personajes desempeñan, quizá aprovechando el menor volumen de audiencia de los mismos respecto de los canales principales. Sí que se observan, sin embargo, detalles en cuanto a las horas de programación, de por ejemplo series como «Dos hombres y medio» que ha sido con cierta frecuencia foco de las reclamaciones presentadas por los espectadores, y que se tiende a iniciar su emisión una vez cumplido el horario de la franja de protección reforzada vespertina.

\section{Conclusiones}

Consideramos que los dos grupos audiovisuales analizados se consideran a sí mismos como responsables al cumplir la legalidad vigente, completar los estándares previstos en materia de responsabilidad social en su triple versión económica, social y medioambiental y sobre todo por sus campañas de concienciación dirigidas al público en general. Sin embargo, la responsabilidad debe ir más allá de la legalidad vigente y además debe abarcar a todos los grupos de interés, aparte de los accionistas e inversores. 
La responsabilidad social debe abarcar a la producción, la distribución y la emisión de los contenidos. En lo referente a la producción de contenidos, consideramos que un punto de mejora dentro de la responsabilidad social sería la producción de programas que no sólo respetaran a la infancia, en lo que está expresamente recogido en la legislación, sino que potenciaran aspectos educativos, ya que tan importantes son la ausencia de elementos negativos como la presencia de elementos positivos para proteger a la infancia. La distribución de los contenidos, tendría que ser capaz de asumir la propia responsabilidad de la empresa productora de los contenidos; siendo garante la cadena televisiva de que la entidad que ha producido los contenidos emitidos cumpla estrictamente la legalidad vigente en España e incluso se pueda considerar también responsable. En la emisión de los contenidos incluimos la publicidad insertada en los mismos. Así, consideramos recomendable que las empresas presten especial atención a la responsabilidad social de los anunciantes; para promover dicha responsabilidad en estos otros grupos de interés, incluso hasta el punto en que las cadenas televisivas pudiesen llegar a vetar a empresas que no sean estrictamente responsables en este sentido.

Por último, sí es destacable el esfuerzo realizado por los dos grupos audiovisuales en aras de la protección a la infancia. La disminución considerable producida en las reclamaciones aceptadas, que llega a ser casi nula en lo que a programas infantiles se refiere; parece demostrar un compromiso claro que tiene su mayor efecto en la "corrección» de la evolución del comportamiento de La Sexta (Atresmedia) y Cuatro (Mediaset), menos cuidadoso de inicio que las cabeceras de ambos grupos. Sin embargo, la repetición de los programas en las diferentes cadenas de ambos grupos no puede echar por tierra ese comportamiento responsable; debiendo prestar, por ejemplo, mucha atención a que la repetición de programas en franjas horarias de protección infantil cumpla también con la normativa, independientemente del horario de emisión original de dicho programa.

En síntesis, la responsabilidad editorial no implica necesariamente una responsabilidad legal pero sí debe incluir una responsabilidad social.

\section{Bibliografía}

Álvarez Monzoncillo, José María (coord.). (2011). La televisión etiquetada: nuevas audiencias, nuevos negocios. Barcelona: Ariel y Fundación Telefónica.

Delgado Sierra, Virginia y Olarte Pascual, M. ${ }^{a}$ Cristina (2012). Responsabilidad social corporativa en el sector de la televisión. Un estudio longitudinal de las memorias de sostenibilidad: $\mathrm{aD}$ Research ESIC. Número 6. Volumen 6. Pp.-112-129 
Fernández Vázquez, Jessica (2012). La responsabilidad social corporativa en los principales grupos de comunicación españoles: incorporación, gestión y análisis de la información a través de sus páginas web: Correspondencia \& Análisis. Número 2 . pp. 112-128.

Francés i Domènec, Miquel (coord.). (2009). Hacia un nuevo modelo televisivo. Barcelona: Gedisa.

Núnez-Ladeveze, Luis; Urusarri, José Antonio y Blanco-Steger Morales, Begońa (2015). La responsabilidad social propia de las empresas de televisión de amplia cobertura: contenidos de riesgo: Comunication \& Society. Volumen 28 (3). pp. 65-82)

Informe de la responsabilidad social corporativa en las memorias anuales de las empresas del IBEX 35, ejercicio 2013, Observatorio de Responsabilidad Social Corporativa

Ley 7/2010, de 31 de marzo, General de la Comunicación Audiovisual.

Ley 31/2014, de 3 de diciembre, por la que se modifica la Ley de Sociedades de Capital para la mejora del gobierno corporativo.

Real Decreto Legislativo 1/2010, de 2 de julio, por el que se aprueba el texto refundido de la Ley de Sociedades de Capital.

www.mediaset.es (consultado: julio de 2016)

www.atresmedia.com (consultado: julio de 2016) 